Journal of Environmental Assessment Policy and Management

Vol. 18, No. 3 (September 2016) 1650014 (31 pages)

(C) The Author(s)

DOI: $10.1142 / \mathrm{S} 1464333216500149$

\title{
Mitigation Measures for Wildlife in Wind Energy Development, Consolidating the State of Knowledge - Part 2: Operation, Decommissioning
}

\author{
Victoria Gartman*, Lea Bulling, Marie Dahmen, \\ Gesa Geißler and Johann Köppel \\ Technische Universität Berlin, Germany \\ *victoria.gartman@tu-berlin.de
}

Received 12 February 2016

Revised 1 April 2016

Accepted 19 April 2016

Published 14 June 2016

\begin{abstract}
During this rapid development of wind energy aiming to combat climate change worldwide, there is greater need to avoid, reduce, and compensate for impacts on wildlife: Through the effective use of mitigation, wind energy can continue to expand while reducing impacts. This is a first broad step into discussing and understanding mitigation strategies collectively, identifying the current state of knowledge and be a beneficial resource for practitioners and conservationists.

We review the current state of published knowledge, both land-based and offshore, with a focus on wind energy-wildlife mitigation measures. We state measures and highlight their objective and discuss at which project stage it is most effective (e.g. planning, construction, operation). Thereafter, we discuss key findings within current wind energy mitigation research, needing improved understanding into the efficacy of wildlife mitigation as well as research into the cost aspects of mitigation implementation. This review is divided into two articles; Part 1 focuses on mitigation measures during planning, siting, and construction, while Part 2 focuses on measures during operation and decommissioning.
\end{abstract}

Keywords: Wind energy; wildlife; efficacy; impact mitigation; onshore; offshore.

\section{*Corresponding author.}

This is an Open Access article published by World Scientific Publishing Company. It is distributed under the terms of the Creative Commons Attribution 4.0 (CC BY-NC) License. Further distribution of this work is permitted, provided the original work is properly cited and is not used for commercial purposes. 


\section{Introduction, Methodology}

As stated in Part 1 of this review, it is important to collectively show what consolidated and agreed upon knowledge exists. (cf. Schuster et al., 2015) and where further research is needed in understanding the efficacy of mitigation measures. Part 1 of this review covers mitigation measures applicable during the planning and siting stages as well as construction in wind energy development. These measures can be applied on a larger scale, including facility characteristics such as turbine type and turbine location at a micro-level. This second paper (Part 2) focuses on smaller scale mitigation measures specific to wind facilities, including all measures during construction and operation where impacts that could not be avoided during siting decisions are then mitigated. This is highlighted in Fig. 1.

We analysed international research up to late-2015 involving mitigation measures for wildlife in the wind energy field through a qualitative review process, based on over 250 documents ranging from scientific (106 peer-reviewed journal articles, books) to grey literature (reports, articles, websites, guidances) to reviewed contributions of recent international conferences such as: Conference on

\begin{tabular}{|c|c|c|}
\hline \multirow{3}{*}{ Planning \& Siting } & Macro Siting & $\begin{array}{l}\triangleright \text { Use Areas of Low Spatial Resistance } \\
\triangleright \text { Avoid Sensitive Areas }\end{array}$ \\
\hline & Micro Siting & $\triangleright$ Turbine Arrangement \& Placement \\
\hline & Facility Characteristics & $\begin{array}{l}\triangleright \text { Facility Design \& Size } \\
\triangleright \text { Increased Visibility }\end{array}$ \\
\hline \multirow[b]{2}{*}{ Construction } & Noise Reduction & $\triangleright$ Sound Barriers \\
\hline & Absence of Animals & $\begin{array}{l}\triangleright \text { Restrictions During Specific Periods } \\
\triangleright \text { Physical Barriers } \\
\triangleright \text { Deterrence }\end{array}$ \\
\hline \multirow{5}{*}{ Operation } & Avoid Attraction & $\begin{array}{l}\triangleright \text { Temporal \& Spatial Land Management } \\
\triangleright \text { Lighting Intensity }\end{array}$ \\
\hline & Luring & $\begin{array}{l}\triangleright \text { Habitat Enhancement } \\
\triangleright \text { Habitat Replacement }\end{array}$ \\
\hline & Deterrence & $\triangleright$ Acoustic, Visual \& Electromagnetic \\
\hline & Curtailment \& Cut-in Speed & $\begin{array}{l}\triangleright \text { During High Abundance } \\
\triangleright \text { During High Risk of Collision }\end{array}$ \\
\hline & Decommissioning & $\triangleright$ Dismantling \& Restoration \\
\hline Decommissioning & Repowering & $\begin{array}{l}\triangleright \text { Dismantling \& Relocation } \\
\triangleright \text { Phased Development }\end{array}$ \\
\hline
\end{tabular}

Fig. 1. Mitigation measure classification. 
Wind energy and Wildlife Impacts (CWW2011, Trondheim, Norway); Conference on Wind Power and Environmental Impacts (CWE2013, Stockholm, Sweden); WinMon.BE Conference: Environmental impact of offshore wind farms (2013, Brussels, Belgium); StUKplus Conference: Five Years of Ecological Research at alpha ventus (2013, Berlin, Germany); Conference on Wind Energy and Wildlife Impacts (CWW2015, Berlin, Germany). We also include German references to provide developers, wildlife experts, and researchers further understanding of current German research practices that would otherwise be difficult to access. As also stated in Part 1, this review covers publications up to late-2015 in a broadtermed approach due to scarce empirical research pertaining to the efficacy of mitigation measures for all wildlife in wind energy, both land-based and offshore.

\section{Avoid Attraction}

Avoidance measures in mitigation include dissuading wildlife away from wind turbines to reduce the risk of collision. Minimizing the area's attractiveness can be through coordinated temporal and spatial land management, minimizing food resources and food availability, and adapting lighting in colour and intensity to avoid bringing wildlife within the rotor swept area or the area directly below the turbine. It is important to distinguish measures underneath the turbine, underneath the turbine blades and the surrounding habitat, and those that attract species offsite and clearly away from the turbine and its surrounding (Behr et al., 2015). This is visualized in Fig. 2.

\section{Land management}

Land management is most effective if temporal and spatial distribution of wildlife, such as for migratory birds, is known (Liechti et al., 2013) as well as being able to establish vegetation or habitat that will not increase prey and thus collision victims (Arizona Game and Fish Department, 2008). Smallwood and Neher (2004) recommend to alter habitat conditions within $50 \mathrm{~m}$ of a wind turbine in order to reduce prey for raptors. For the red kite (Milvus milvus), an investigation in Germany by Mammen et al. (2011) states keeping the vegetation fallow (i.e. crop-free) in the surrounding area and restrict agricultural management activities (e.g. mowing) before mid-July. Research by Krone et al. (2013) observed the presence of common buzzards and red kites together with adult white-tailed eagles hunting above a wind facility after farming dunghills were piled, suggesting to avoid activities that increase attraction. Another 


\section{Gartman et al.}

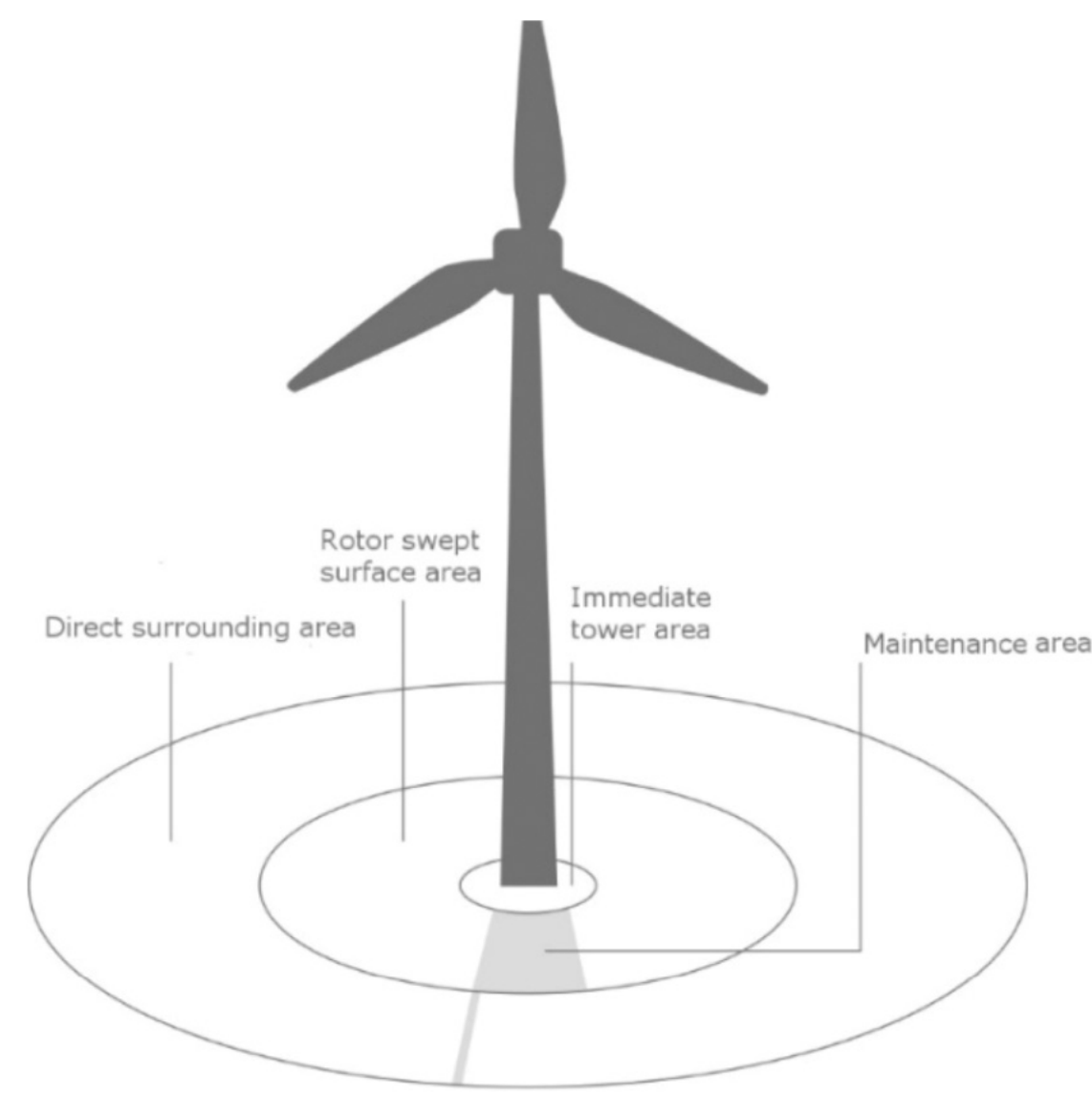

Fig. 2. Different prevention measures can be used in the surrounding environment, depending on the distance to the wind turbine (Behr et al., 2015).

recommendation given from Allison (2012), is for the golden eagle (Aquila chrysaetos) as a form of offsetting any mortality through increasing prey in parts of the range where eagle productivity or adult survival is lagging. However, this is only in theory and not yet tested.

There are a number of recommended factors in minimizing the availability of food resources around wind turbine structures, particularly with raptors. Smallwood and Neher (2004, 2009); Smallwood (2007), Smallwood and Karas (2009) recommend a number of measures to reduce prey vulnerability when raptors are foraging, such as removing all artificially created rock piles as they attract potential prey to live in the rocks. (Smallwood and Neher, 2009) or exclude cattle from turbine areas to discourage habituation by ground squirrels or other small prey (Smallwood and Neher, 2004; Orloff et al., 1992). 
Additionally for raptors, there have been ambiguous investigations into mitigating attraction options underneath turbines. Smallwood (2007) investigated comparisons between areas of different rodent controls for the burrowing owl (Athene cunicularia hypugaea), noting to cease rodent control as the measure did not change bird behaviour, possibly increasing mortality. In Portugal, Cordeiro et al. (2013) investigated planting native scrub underneath turbines to obtain denser vegetation and thus become less attractive for kestrels (Falco tinnunculus) and establish open patches inside these scrub areas promoting extensive goat grazing away from turbines so the habitat stay heterogeneous. These open scrub patches would increase prey density in areas with lower risk of collision to turbines for kestrels when foraging (Cordeiro et al., 2013). Avoiding increased food resource and availability is a prime example of the difficulty in comparing mitigation efficacy due to the species-specific measures needed, geographical region and location, and the encompassing surrounding habitat or environment.

Through management, developers can avoid the reduction in fitness not only for birds, but also for bats (Mascarenhas et al., 2015). Currently, there are only hypothetical conclusions as to why bats have high collision mortality with turbines: They may consider them pairing or mating stations (Cryan, 2008) or trees and snags to roost (Kunz et al., 2007); they may be investigating the structures as they are "new" in their airspace (Horn et al., 2008); or they are attracted via insects available from the lighting or their similar migration paths (Rydell et al., 2010). Investigation into if and why bats are attracted to wind turbines is needed, and further investigation could be into the feeding patterns of insects parallel to turbine height (Part 1, Sec. 5.1) or lighting intensity (Sec. 2.2), causing increased risk to collision for bats during feeding.

During operations and maintenance when human activity is lower, non-volant wildlife can move into the area, whether it be their original habitat or new habitat with new attractive features (e.g. water, food, nesting and perching) (Boarman, 2003). This may cause human-induced casualties or predation causalities of species threatened or endangered (Lovich and Ennen, 2013). Even for invertebrates, while it was found through an investigation that a decline in species richness occurs when the wind farm was in operation (Santos et al., 2010), no recommendations have been given on how to manage or improve the area to reduce impacts.

\section{Lighting intensity}

Lighting intensity can attract or disorient wildlife with the aim of deterring species to avoid collision, but the responsiveness from lighting is still poorly understood 
(Arizona Game and Fish Department, 2008; Johnson et al., 2007). Lighting can all achieve different levels of visibility which can deter birds (onshore) or attract them (offshore). Recommendations of removing non-flashing or steady burning (red) lights can be most effective and economically feasible (as observed by Gehring et al. (2009) on communication towers) and Johnson et al. (2007) suggest not to use strobe lights. For migrant birds, Kerlinger et al. (2010) investigated that steady-burning red lights attract migrants but flashing ones do not, as they did not find evidence to suggest that flashing red lights cause large numbers of fatalities. For bats, studies have observed that mortality is not statistically significant at turbines with lighting than those without (Fiedler et al., 2007; Erickson et al., 2004; Johnson et al., 2004), yet Turowicz et al. (2013) states in her preliminary results that bat activity can be controlled around wind facilities via the use of light. Due to inconclusive results, more recent studies need to be conducted to verify previous studies. Ballasus et al. (2009), from an evaluation of 400 studies, view artificial lighting as a threat to birds and bats and recommend reduced lighting.

As lighting of turbines is not standardized, it must fall within the country's aviation transport regulations which varies. Apart from this, they should also be set within the minimum number, minimum intensity, and minimum number of flashes based on the country's regulation (Manville, 2005). Solid red or pulsating red incandescent lights should be avoided as they appear to attract night-migrating birds (e.g. passerines) (U.S. Fish and Wildlife Service, 2012; Johnson et al., 2007; Manville, 2005). As previously stated, lighting attracts insects and thus can attract bats (insect density correlates with bat activity (Horn et al., 2008) and birds (Arizona Game and Fish Department, 2008; Drewitt and Langston, 2008). Yet for bats, Johnson et al. (2003) observed that the mean number of bat mortalities at lighted turbines was not significantly higher than the mean number of fatalities at unlit turbines. This is also confirmed by Bennett and Hale (2014) that synchronized, flashing red aviation lights does not appear to be a potential cause in bat fatalities at wind facilities. Various opinions in lighting are given but all conclude to avoiding lighting turbines when and where possible.

It is still unknown how lighting intensity offshore can affect migrant and seabird species movement; whether it be viewing the facility as an obstacle and flying around it, becoming disoriented i.e. have a 'trapping effect', or becoming attracted to them to rest or forage (Blew et al., 2013; Hüppop et al., 2006; Johnson et al., 2007). Similar to land-based lighting requirements, offshore wind facilities must also install lighting for general aviation and shipping. Hötker et al. (2006) states for both that flashing red safety lights be reduced to a minimum and intervals between each flash be made as large as possible. Only one investigation into night time lighting has been conducted on migratory birds by Poot et al. (2008), 
concluding nocturnally migrating birds were disoriented and attracted by red $(54 \%)$ and white $(60 \%-81 \%)$ lights, but were clearly less oriented by blue $(4 \%-5 \%)$ and green $(12 \%-27 \%)$ lights, particularly on overcast nights. Thus, recommendations to use lights with short wavelength radiation could significantly decrease collision risk. This can be seen in research at a gas production platform in the North Sea where lighting was changed to 'low in spectral red', and birds were impacted 2-10 times less than normal white and orange lightings (Laar van de, 2007).

Blew et al. (2013) presented that for offshore wind facilities and specific turbines 'the less the lights, the better', and to rather install ship safety lights on corners of the facility or use demand lighting as well as minimizing lighting intensity of facilities. This is observed and recommended by Hill (2015) that as birds may become attracted to the light during adverse weather, the possible use of need-based lighting when aircrafts or ship vessels approach (using appropriate detection technology) could be effective. Deflectors, as stated in Part 1, Sec. 5.2, is also recommended offshore (Blew et al., 2013). Additionally, current research has mainly focused on raptors and little for bats or any other species groups in or around wind facilities. This can most likely be due to minimal direct impacts, but are still nevertheless impacted through light intensities and land management measures that may alter, displace, or disorient them. There has been significant research on such issues like artificial lighting (Rich and Longcore, 2006), where mitigation measures can be applicable but none directly involving wind energy.

\section{Luring}

Luring wind turbine sensitive species away can be achieved through habitat enhancement offsite or replacing habitat lost, i.e. compensation. These can include the creation of ponds (Peste et al., 2015), increase of prey or food availability outside the wind facility or potential impacted area (Paula et al., 2011), or establishing conservation easements on nearby private ranch lands or planting 'lure crops' (Mammen et al., 2014) to attract birds away from depredation sites (Walker et al., 2005).

\section{Habitat enhancement}

As stated in Sec. 2, reducing prey availability within the wind facility and enhancing feeding opportunities or foraging habitats offsite is most recommended for raptors (Mammen et al., 2011; Walker et al., 2005; Robson, 2011; Paula et al., 
2011; Paula, 2015). An observation by Robson (2011) for the hen harrier (Circus cyaneus) in western Scotland Argyll showed an increase of 32-42\% in flight activity including three breeding attempts in a created habitat enhancement area next to the facility. However, he noted that there was no difference within the wind facility, which could be due to prey availability not being significantly different from the new habitat area. In Spain, observation by Paula et al. (2011) also on golden eagles investigated prey management through the restoration of wild rabbit (Oryctolagus cuniculus) populations through habitat management. Their study, comparing a control area to a managed area, showed the increase in abundance of wild rabbits in the managed area coupled with two eagle couples intensely using the managed area as well. Wind facilities should cooperate with habitat enhancement areas to ensure prey availability be lesser in the facility area than the enhancement area. Rasran et al. (2010) observed a higher fatality rate for raptors at turbines surrounded by only arable land, as food availability may actually be higher around these tower bases where vegetation is less dense. Conclusively, providing better feeding opportunities or foraging habitats offsite is a beneficial form of compensating for negative impacts, but further investigation for best practices are lacking.

\section{Habitat replacement}

The replacement of habitats or measures establishing new artificial habitats is frequent in mitigation, yet empirical research is absent for wind energy developers to properly mitigate their impacts. There have been a number of mitigation options recommended for groups of species such as raptors and bats, using both natural and artificial means.

Early research from Walker et al. (2005) observed before and after construction of a wind facility in Argyll, Scotland and its impact on the Golden eagle's (Aquila chrysaetos) range. An area of plantation forestry was felled nearby the wind facility to draw eagles away from the facility to reduce collision risk; observations showed eagles in the nearby enhancement area of felled trees three times as much than before the trees were felled, thus shifting their range away from the wind facility. While Walker et al. (2005) only observed a pair of eagles, this initial study strengthened the need to establish a species-specific area away from facilities to reduce risk of collision. Additionally, research by Dorka et al. (2014) in Germany's Black Forest noted negative impacts on the woodcock (Scolopax rusticola), thus recommending the need for considering special habitats compensation during wind energy planning and evaluation. 
Additionally for raptors, artificial nesting platforms have been recommended for species such as osprey (Pandion Haliaeetus) and golden eagle (Johnson et al., 2007) as they can be quickly created, manipulated, and monitored with little economic costs. Also the establishment of artificial feeding stations (i.e. vulture restaurants), particularly for scavenging bird species, as investigated by CortésAvizanda et al. (2010), Martínez-Abraín et al. (2012) and Camiña (2011a) can be beneficial in luring at-risk species away from turbines and facilities. Other recommendations include relocating supplemental feeding stations away from turbine locations (Martínez-Abraín et al., 2012), closing nearby rubbish dumps (observed in Spain) (Camiña, 2011b), or relocating any dead carcasses offsite (to be tested) (Allison, 2012) to draw raptors away from the turbines. The state government of Saxony-Anhalt, Germany has provided a 'Red Kite Protection Program', where they recommend fenced-in feeding sites (LAU, 2014). Generally, moving any anthropogenic food sources (Northrup and Wittemyer, 2013) for raptors or scavenging birds lowers the densities of prey animals in the area and thus minimizing carrion availability (Manville, 2005). Further recommendations for raptors include payments to nearby landowners to protect nest trees outside of the wind facility, fencing riparian areas up to $24 \mathrm{~km}$ ( 15 miles) away from the facility to enhance the recruitment of deciduous trees for future raptor nesting, or provide research subsidies in determining which mitigation measure is most appropriate (Johnson et al., 2007).

For bats, the creation or establishment of fallows and hedgerows as new foraging habitat can help as compensation for facility impacts, especially around agricultural or farming areas, as recently investigated by Millon et al. (2015). Yet more commonly is the establishment of bat-boxes, used in forested or agricultural areas, as another form of habitat replacement which can help in the short-term and can be economically feasible (as recommended by Peste et al., 2015). Yet these boxes should be in combination with new roosting habitats as they are not complete substitutes for any roosts destroyed, and should be as close to the roost lost similar in size, height, and aspect (Mitchell-Jones, 2004). Little research shows how effective this form of mitigation is for bats and requires further investigation as bat, and even bird, boxes are only temporary housing. As bat research is still investigating population level impacts from wind turbines, habitat enhancements and replacement, e.g. compensation scenarios, will be difficult to establish; thus bat mitigation must rely heavily on avoidance and minimization measures (Rodrigues et al., 2014).

Nevertheless, land-based habitat management can be largely beneficial to reduce collision risk. This can also be said for non-volant species, such as the Iberian wolf in Portugal, where compensation measures have been integrated into EIA's as 


\section{Gartman et al.}

a measure of wolf conservation with possible measures including forest management, reduction of conflict i.e. K-9 poison detection, incentives to traditional herding, distribution of shepherd dogs, as well as the re-introduction of wild prey, public awareness, and restricted hunting areas (Brotas et al., 2015). Direct relocation of individuals can be considered a compensation measure, but be challenging when selecting a new habitat for the at-risk species (e.g. the desert tortoise (Gopherus agassizii)) (Heaton et al., 2008).

This mitigation option helps to protect and enhance bat and bird populations at biologically important locations, but only when designed and implemented properly. As replacing habitats can be incredibly difficult and species-specific, further research funding can be given to determine most effective mitigation measures.

Habitat enhancement and replacement offshore has mainly focused on the establishment of environmental and marine protected areas (or marine reserves) (Ashleyet al., 2014) within the facility and reef creation or fish aggregating devices (e.g. scour protections) around turbine foundations (Inger et al., 2009; Petersen and Malm, 2006). A BACI investigation by Pearce et al. (2014) provides evidence that OWF can become marine reserves noting the establishment of Spinulousa spinulousa reef habitats 18 months after construction and site completion at the UK Thanet Offshore Wind Farm. However, while the foundation is considered a positive impact rather than a mitigation measure, it nevertheless can and has been allowed to act as habitat replacement and enhancement of the impacted area for offshore wind developers (Vaissière et al., 2014; Wilson and Elliott, 2009). The establishment of OWF has showed an increase in not only some fish species and thus benthos (as investigated by Reubens et al. (2011) on pouting (Trisopterus luscus)) but also marine mammals such as the harbour porpoise due to increased food availability and the absence of vessels (as investigated by Scheidat et al. (2011), Andersson and Öhman, 2010)). There is mention of restoring ecosystems via the creation of seagrass meadows, showing large variations in success (Ganassin and Gibbs, 2008).

Habitat replacement for seabirds and migratory birds offshore is a new topic with little research. Recommendation from Cook et al. (2011) states the use of decoy towers placed around the facility perimeter can lure species away from entering. Cook et al. (2011) states, however, the effectiveness of decoy towers is low as it is only effect for sea ducks, divers, and auks. There is also recommendation for closing industrial fisheries, eradication of invasive predators, new nesting habitats by Furness and Wanless (2015). Thus, OWF research has been limited in this field as offshore research is still focusing on its impacts and establishing reaction thresholds for bird species (Hill et al., 2014). 


\section{Deterrence}

Acoustic devices, electromagnetic (EM) fields, or visual deterrents, can purposefully alarm and frighten wildlife in order to prevent them from entering a wind facility or nearing a turbine. By directing them away without permanent harm done, the risk of collision or long-term damage decreases. Additionally for offshore, deterrence during construction can lower the risk of any long-term damage (as discussed in Part 1, Sec. 6). However, there are varying recommendations of these deterrence mechanisms and their effectiveness as researchers' primary concern is the eventual habituation to these deterrence devices or becoming a hazard to wildlife, and even to humans (Gilsdorf et al., 2002; May et al., 2015; Bishop et al., 2003; Johnson et al., 2007).

Birds on average hear between $1-5 \mathrm{kHz}$ less well than humans, thus deterrents are not as effective and can resort to habituation or ignored completely (Dooling, 2002). These devices are recommended, but with a combination of other mitigation measures and their timely use, as they can be useful in reducing wildlife while being cost-effective (Gilsdorf et al., 2002; Cook et al., 2011). It is also important to adapt deterrence measures based on the particular or at-risk species (Martin, 2011). Yet, little empirical research has been done directly involving wind turbines, as most observations occurred almost a decade ago at airports or towers.

Deterrents can be emitted through human observation or through automated real-time surveillance systems such as DT Bird (Riopérez and Puente, 2013) or Merlin Aviation Radar System (ARS) (DeTech Inc., 2014). While they state they are effective, further field studies into these surveillance systems is needed.

\section{Acoustic}

An acoustic deterrence is an auditory technique that can be relatively effective for birds but only in the short intervals (Bishop et al., 2003; Marques et al., 2014). Distress calls, pyrotechnics, and sounds of gunfire can be most effective (Bishop et al., 2003; Mascarenhas et al., 2015) while artificial sonic, or ultrasonic devices and high intensity sounds can be least effective and even unsafe (Bishop et al., 2003; Gilsdorf et al., 2002). Bio-acoustic devices such as distress calls or highintensity sonic sounds can be effective but is species-specific and may end up inviting other curious species to the area (Bishop et al., 2003).

Ultrasonic acoustic devices for bats have recently undergone investigation to help reduce bat fatalities (Arnett et al., 2013b). While ultrasound may discourage bats from moving closer, the effect is limited by distance and there is yet to be an operational deterrent device properly developed for bats (Arnett et al., 2013b; 


\section{Gartman et al.}

Arnett, 2015; Hein, 2014). More research to refine the efficiency of using an acoustic deterrence for various weather conditions and for particular species' behaviours is underway (Hein, 2014).

\section{Electromagnetic}

The use of microwave signals (Johnson et al., 2007), magnets, or EM waves (Harris and Davis, 1998) has been recommended for birds as there are some positive aspects using this form of deterrence (e.g. works day and night, can penetrate fog and clouds, travels at the speed of light), but the concerns of imposing a health risk or disorienting wildlife as well as humans (e.g. thermal heating) (Voigt et al., 2015; Harris and Davis, 1998) are higher. Nicholls and Racey $(2007,2009)$ investigated EM fields on bats using a small, pulsed EM radar system, concluding that it would have adverse effects possibly influencing the development, reproduction, and physiology of insects, mammals, and birds. Nicholls and Racey (2009) as well as Voigt et al. (2015) state that measures for repelling bats or successfully mitigating bat collisions from wind turbines have not been proven to be efficient or successful, thus future testing in the effectiveness of $\mathrm{EM}$ is needed.

\section{Visual}

Flashing, rotating, strobe or search lights lasers (Cook et al., 2011; Clarke, 2004; Gilsdorf et al., 2002), or moving and shiny devices (Mascarenhas et al., 2015; Bishop et al., 2003) are visual cues which could be added to help reduce bird collisions; but they have their drawbacks. It is important to note most research regarding visual deterrents for wind turbines is minimal (mainly at airports or in scientific settings). Cook et al., (2011) briefly discuss visual deterrents (i.e. lasers) for wind energy offshore, but there are no investigative measures into visual deterrents and their effectiveness around wind turbines. Additionally, visual deterrents can be counterproductive in lighting, as they can become briefly blinding causing confusion. Supplementary to Part 2, Sec. 2.2, lighting intensity and Part 1, Sec. 5.2 increased visibility in lighting is difficult to compare and assess as there are variations which can draw one species to the facility while deterring another. Visual deterrence is separate of visual lighting intensity due to the goal each measure aims to achieve; visual deterrence aims to increase the visibility of a wind turbine and to deter particular species away to avoid collision, while reduced lighting aims to avoid attracting species to the wind facility. 
Thus, it is important to take into account species-specific behaviours as the ability to deter species is dependent on habitat and foraging preferences (Martin and Shaw, 2010). There is no empirical proof as to how effective deterrents are with wind turbines, as much of this research looks at power lines, buildings, airports, and towers and research is fairly old. The placement of deterrents is also not discussed and requires further investigation.

\section{Operational Minimization}

The use of curtailment, i.e. establishing operational stopping periods can be most effective during periods when at-risk species are within the facility or nearby, enabling a shut-down period to reduce the collision risk and avoid going over previously identified activity thresholds for particular species. These time periods can be identified based on variables such as seasonality (Manville, 2005), weather movements (Liechti et al., 2013; Hüppop et al., 2006; Hein, 2014), and species (Johnson et al., 2007; Smallwood, 2010). Nevertheless, a number of measures such as 'shutdown on demand' or recent research into seasonal behaviours has improved curtailment mitigation during operations. Facilities can shut down turbines when a particular endangered species, for example the U.S. California condor (Gymnogyps californianus) enters the facility airspace or spotted nearby through GPS tracking and observers (Sheppard et al., 2014; Sutter et al., 2012). Establishing curtailment measures during migratory periods, or for certain individual species most prone to collision such as raptors (Smallwood, 2010) or treeroosting bats (Johnson et al., 2011) are also beneficial in reducing collision risk during wind facility operations. Additionally, curtailment can be used for specific turbines within high mortality 'hot spots' (Piorkowski et al., 2012) where wind facilities can shut down these hot spot turbines based on times, seasons, or year based on monitoring to lower collision mortality without compromising the energy generation of the rest of the turbines not impacting mortality rates (Piorkowski et al., 2012). During or after agricultural cultivation activities (e.g. mowing or harvesting) that attract collision-prone species, temporary shutdown can be a useful measure. In Germany, agricultural management can trigger shutdown for 1-3 days after the event during daytime hours particularly aiming at the protection of foraging raptors (Behr et al., 2015).

Implementing threshold wind speed for turbine start-up, i.e. cut-in speed, and feathering (changing the blade angle) is either through operational schedules or the use of algorithms based on seasonal activity of species (as investigated by Hurst et al., 2013, Behr et al., 2011), as well as temperature (Arnett et al., 2006), wind speed (Voigt et al., 2015), and humidity (Behr et al., 2011). 
Increasing the cut-in speed has been particularly useful for bats as they are relatively known to be active at current rotor heights during wind speeds below $6 \mathrm{~m} / \mathrm{s}$ (Manville, 2005; Hein, 2014), where net energy production is low as well, and can drastically reduce bat fatalities from 60-80\% (Voigt et al., 2015; Arnett et al., 2013a; Baerwald et al., 2009). Seasonal bat activity can be based on regional climate patterns as well as local weather conditions where the wind facility is located (Arnett et al., 2013a) as bat activity is fairly predictable, occurring from sunset to sunrise (Hein, 2014), primarily in late summers of MidJuly to end of September (Hein, 2014; Rydell et al., 2010), and when temperatures are greater than $10^{\circ} \mathrm{C}$ (Hein, 2014), but is dependent upon the particular species.

Investigations into cut-in speeds for bats within the last decade have given impressive empirical evidence on how much the cut-in speed should be raised (Arnett et al., 2009, 2011; Baerwald and Barclay, 2009; Lagrange et al., 2013; Georgiakakis et al., 2012; Ledec et al., 2011; Wellig and Arlettaz, 2013; Rydell et al., 2010; Hein, 2014). Conclusively, most recent studies show a 50\% reduction in bat mortality when developers raise their cut-in speed $1.5-3.0 \mathrm{~m} / \mathrm{s}$ above normal cut-in speeds (i.e. 3.5-4.0 m/s) (Arnett, 2015). With the inclusion of bat-friendly algorithms (Korner-Nievergelt et al., 2011; Behr et al., 2014, 2015) or other season-specific, multivariate models rather than operational changes based on wind speeds alone, could decrease shut-off times becoming even more economically feasible for wind developers (Weller and Baldwin, 2012). Bat-friendly systems and software such as Batcorder, Anabat SD1 (bat detectors), ProBat, and BATMode (online data tools) are becoming a standard method, particularly in Germany (Behr et al., 2014, 2015), and help decreasing the amount of unnecessary energy loss or economic costs (Brinkmann et al., 2011).

Migratory birds usually consist of small nocturnal passerines and are driven by weather, migrating within only a couple of nights (or days) out of the year (Aschwanden et al., 2013). Liechti et al. (2013) discusses the essential application of a shut-down regime via thresholds based on bird migration intensity. They state that the effect of expected mortality based on population demographics of involved species defines these thresholds and establish a 'rule of thumb' for developers that 'an acceptable number of additional fatalities by wind turbine(s) should be about two orders of magnitudes below casualties caused by tall man-made structures' (Liechti et al., 2013).

Curtailment offshore has particularly focused on seabirds and migratory birds offshore, recommending shutdowns during mass migration (Hill, 2015; Cook et al., 2011), bad weather (Hill, 2015; Kubetzki et al., 2011; Bellebaum et al., 2010), at night (Hüppop et al., 2006; Kubetzki et al., 2011), and those close to 
breeding colonies during high flight occurrences (as observed by Everaert and Stienen, 2007). There have also been site-species specific investigations such as by Singh et al. (2015) for the offshore Cape Wind Project in the U.S. for the common loon (Gavia immer) in developing a model giving specific recommendations when to operate curtailment. Another offshore investigation by Villegas-Patraca and Herrera-Alsina (2015) for Franklin's gull (Leucophaeus pipixcan) in Tehuantepec Isthmus Mexico, recommends establishing curtailment to occur in April when winds come down from the north. However, effective curtailment strategies offshore have yet to be realized through empirical research.

Curtailment for raptors has been noteworthy. A significant study was done on raptor mortality rates and wind turbine curtailment measures in Tarifa, Cadiz, Spain a major migratory bottleneck north of the Strait of Gibraltar. Lucas et al. (2012) investigated mortality rates for the Griffon vulture at 10 out of 13 wind facilities in this area by conducting turbine shutdown programs from 2008 to 2009 , and compared rates from a no stopping program in 2006-2007. Results showed a highly significant difference in mortality rates between the years and among individual turbines that were deemed 'most dangerous', concluding that selectively stopping a few turbines during a few months of the year can significantly reduce mortality rates by more than 50\% (Lucas et al., 2012; Muños Gallego et al., 2011). Their recommendation for vultures include short stops of turbines between the first $2 \mathrm{~h}$ after sunrise until the last $2 \mathrm{~h}$ before sunset, allowing only a $0.07 \%$ reduction in energy production (Lucas et al., 2012). Research by Tomé et al. (2015) in Southwest Portugal investigated a wind facilities' Radar Assisted Shutdown on Demand (RASOD) protocol with pre-defined criteria based on intense migration or presence of soaring birds. Over the research period, while they estimated a minimum of 570-1550 individuals were at risk with colliding with the turbines, the use of RASOD increased the efficiency while minimizing the average shutdown period and zero deaths of soaring birds occurred (Tomé et al., 2015).

Other studies recommend seasonal shutdowns, for instance, at the Altamont Pass Wind Resource Area (APWRA) for raptors such as red-tailed hawks, American kestrels, and burrowing owls (as observed by Hoover, 2002 and Smallwood, 2008); however, seasonal shutdowns were only partially implemented (i.e. half-winter shutdowns instead of full-winter) and thus remained insignificant. Hoover and Morrison (2005) mentions powering down topographically-specific turbines during certain weather conditions, but does not empirically evaluate the effectiveness of this measure.

Recent technological advances can help input several variables (e.g. weather, migration behaviours) and determine curtailment periods, as well as even shutting 


\section{Gartman et al.}

down the turbines on command to reduce collision mortality with the blades. For bats, echolocation detectors directly installed within the nacelles can help with programmed shutdowns occurring when bat activity exceed pre-determined thresholds (Martin, 2015). Using field observers can be beneficial, but the use of SCADA (for birds see Davenport et al., 2011), DTBird (birds and bats Riopérez and Puente, 2013), or CHIROTECH (bats Lagrange et al., 2013) as control and surveillance systems or the use of thermal cameras can detect birds and bats in real time and can even program the turbine(s) to shut down. These have been beneficial in not only reducing collision risk but have also in monitoring and better understanding at-risk species for further research. However, those visual systems primarily detect large birds such as raptors whereas detection of other smaller species (e.g. passerines) is not possible. Moreover, other large objects such as aircrafts are detected as well and can lead to high amounts of false positives possibly resulting in false stop events (Hanagasioglu et al., 2015). Consequently, this promising technology needs further research and testing.

\section{Decommissioning \& Repowering}

Progressive technology in this industry has allowed wind turbines to become larger and taller in rotor diameter and height, as well as being more energy efficient. With turbines having a lifespan of on average 20 years (Nugent and Sovacool, 2014), the stage of decommissioning older-generation turbines built in the late 1990s has already begun and research in decommissioning and repowering has only been within the past decade. Repowering facilities are able to generate higher energy levels from lower wind levels, giving the opportunity to reduce fatalities at wind facilities with historically higher collision rates by minimizing the number of turbines (Lucas et al., 2012) and by spatially placing turbines in an improved pattern or design (Turvey 2015; Smallwood, 2015). Through decommissioning and repowering, it is important to establish mitigation measures during the dismantling phase and establishing any removal offsets, understanding measures needed during gradual removal phased development, and in the relocation of new turbines.

\section{Dismantling \& repowering}

Removing harmful or potentially hazardous turbines (Smallwood, 2007; Smallwood and Neher, 2009; Thelander and Rugge, 2000) as well as any broken or nonoperating turbines (Smallwood and Neher, 2004; Smallwood, 2008) can be most effective if mortality at a particular wind turbine is unacceptable (Northrup and 
Wittemyer, 2013; Barrios and Rodríguez, 2004). The relocation of turbines has been briefly mentioned (Smallwood, 2008; Drewitt and Langston, 2006) with only short recommendations of relocating hazardous turbines so as to effectively reduce collision risk.

There have been investigations and guidelines for the California Energy Commission (USA) in the replacement of turbines in California (California Energy Commission and California Department of Fish and Game, 2007), namely at the APWRA which have helped shape research in this field mainly for raptors (Smallwood and Thelander, 2008; Smallwood and Thelander 2005; Smallwood and Thelander, 2004; Thelander and Rugge, 2000). Smallwood and Karas (2009) investigated raptor and bird fatality rates between a repowered turbine area and an old-generation turbine area within the APWRA, finding that fatality rates did not differ significantly. As there was an overall decrease in bird fatalities, bat fatalities significantly increased, nearly 14 times greater (Smallwood, 2010), at the repowered turbines compared to the old-generation turbines. Conclusively, results were similar to Krijgsveld et al. (2009) as mentioned in Sec. 5.1, where fatality rates did not significantly differ but the overall risk was lower with the newer and fewer turbines based on the energy per megawatt of rated capacity (Smallwood and Karas, 2009). Rodrigues et al. (2006) recommends repowering to occur at the time of the year with minimal disturbance.

Johnson et al. (2007) agrees that replacing smaller turbines with larger ones not only allows more generation of energy but also reduces raptor collision risk. It is interesting to note that turbines 10 years ago were smaller, and further investigative research into the newer taller turbines is needed. Research investigated by Gaedicke et al. (2013) on repowering effects on raptors show that collision risk increases at new turbines than at older generation turbines due to the rotor size, but as the rotational speed is lower due to its size, the probability of collision is lower. Additionally, the potential risk to nocturnal migrant passerines and bats becomes greater, and the concern with repowering has shifted from raptor mortality to bat mortality (Rydell et al., 2010). Voigt et al. (2015) recommends careful attention in old permits when repowering as they may not have considered new measures, and for new groups of species (e.g. open-air foraging bats that were not a concern for old-generation turbines as they flew above the rotor-blade zone).

As current $O W F$ s have not yet reached decommissioning phase, only options and possible next steps have been discussed. Smyth et al. (2015) recommend a 'renewables-to-reefs' program, which allows partial removal of the turbine foundation leaving in place scour protection or any hard structures. These structures become important habitats for fish or crustaceans, leading to stocks with commercial and recreational value. Fishing opportunities, eco-tourism, and 


\section{Gartman et al.}

conservation could occupy these old OWF locations (Smyth et al., 2015), but further investigation as to the full benefits of reef creation are needed. As decommissioning is a number of years away, many developers have not discussed or evaluated impacts during decommissioning as, "[b]y then, knowledge and techniques should be improved, and the best solutions available at that time will be adopted" (Vaissière et al., 2014).

\section{Phased development}

The gradual expansion of a wind facility can help avoid negative impacts and biodiversity loss of that particular area. Through first establishing part of a wind facility, then monitoring the facility on its environmental impacts, and based on if impacts are kept low, the developer could expand the wind facility. However, there is need to consider the extent to which the initial phase of development is representative of the anticipated final development. Importantly, there is only research from the World Bank (Ledec et al., 2011) which recommend phased development. Ledec et al., (2011) discuss the example of an Uruguay wind facility, where the first five turbines were more of a pilot study to see their impact on the surrounding species and if successful, based on their monitoring results, be able to add the additional five more turbines to the adjacent area. This phased development can also be a financially acceptable move, and can be chosen based on non-environmental reasons as well (Ledec et al., 2011). Yet further research is needed whether the effects proportionally scale-up during phased development or compare the initial phase's spatial scale and final development in terms of the spatial distribution and habitat use by potentially affected species.

Conclusively, these stages in wind development give a prime example of the overlap mitigation measures can apply to and help in minimizing displacement, collision risk, and mortality. For instance, an impact assessment investigation by Dahl et al. (2015) for repowering the Smøla Wind Facility in Norway suggest mitigation measures discussed in increased visibility (e.g. painting turbines and turbine blades), deterrence (e.g. UV lighting), and operational minimization (e.g. selective shutdown). Repowering is also a chance to reinvestigate direct responses from wildlife (Lovich and Ennen, 2013) as new turbine construction can give better insight into which mitigation measure is most effective.

\section{Discussion}

In providing a comprehensive understanding of where current research and practice lies, a significant point to be made is the lack of evidence into the efficacy 
of each mitigation type. This is primarily due to the lack of research and varied research methodologies. Below, each mitigation type is construed based on the peer-reviewed and grey literature:

- While avoiding attraction is a well-known measure that has been implemented (e.g. minimal lighting, carcass removal) mostly based on common sense, minimal research confirms its efficacy.

- Collecting research in measures effectively luring species away from turbines and wind facilities can be difficult, as this can fall within an "Output $\longleftrightarrow$ Outcome scenario" where, for instance, while ensuring minimal food sources can be effective in avoiding attraction within a facility, it remains uncertain how effective the measure truly is when comparing one area to another. In short, luring works well for raptors, but its effectiveness is uncertain. This can be similar to the use of bat boxes or any form of artificial roosts where its effectiveness can be difficult when comparing offsite or other facility roosting areas. As luring mitigation can be dependent upon the species whose habitat has been disturbed or destroyed, the use of a habitat management scheme implemented in the planning stages is most beneficial. It is important that habitat enhancement and replacement should focus on measures which improve species' hunting habitats, manage prey populations, and protect breeding sites (Paula, 2015). Additionally here, there is potential in better involving local communities support and knowledge as well as establishing an adaptive management framework. While adaptive management can be applicable in many stages, in this context it allows the wind facility project to adjust accordingly based on the ecosystem's response (Paula, 2015) and can effectively establish a well-placed and wellcoordinated replacement habitat.

- Deterrence mechanisms appear to be promising and should consequently receive more attention by researchers in order to provide developers and decisionmakers with recommendations of effective measures and devices aiming to reduce collisions and mortality. While the use of ultrasonic devices can be most effective for deterring bats, there is still need for an effective (and internationally applicable) device as well as continued monitoring to ensure efficacy of these mechanisms. Additionally, determining long-term effectiveness is needed, to understand if habituation to deterrence mechanisms occurs. Even if a wind facility is sited and placed in the most efficient location (economically and ecologically), the risk of collision will remain and the use of deterrence mechanisms can help to further reduce collisions, proving them necessary.

- For operational minimization, curtailment measures are proven effective for bats and raptors. Further understanding and empirical evidence of revenue losses 


\section{Gartman et al.}

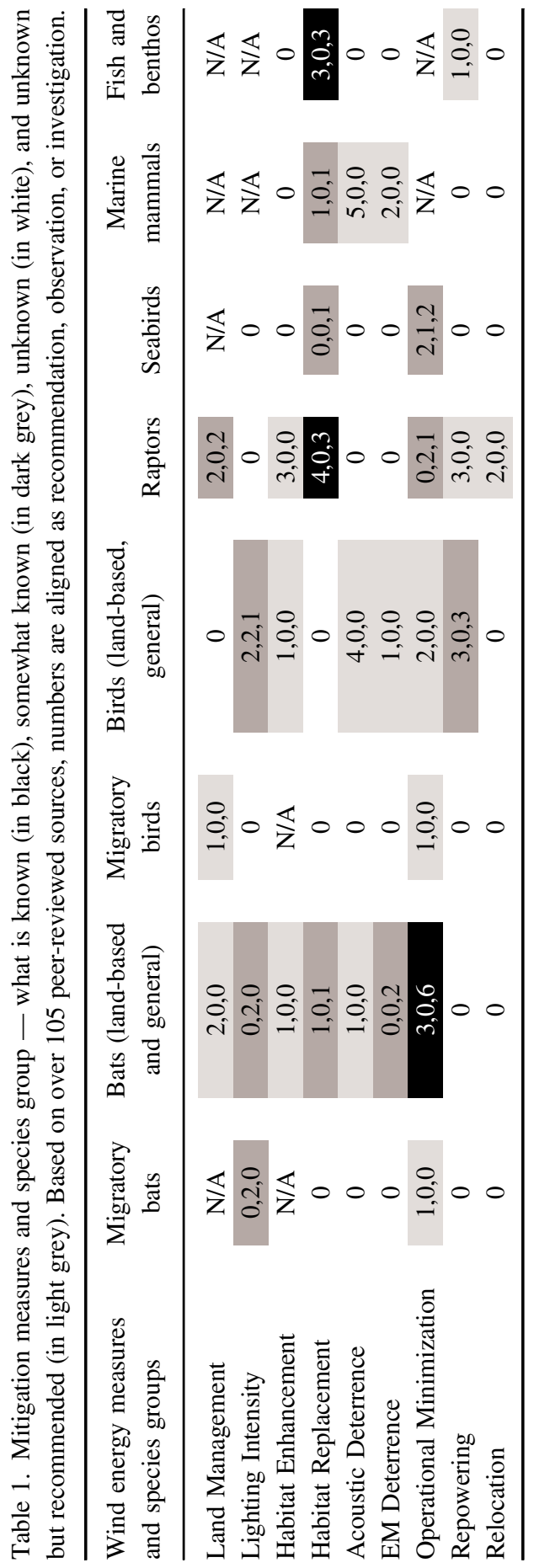


during curtailment periods is required for not only wind facility operators to better comprehend, and thereby use curtailment more efficiently, but also for developers to ensure predictability, frequency, and duration of the curtailment measures. Curtailment could be applicable in all regions and offshore, but research at offshore facilities and for migratory species is needed.

- Lastly, decommissioning and repowering has little investigative research as wind facilities are within the first decade of decommissioning and repowering turbines (and this phase has not occurred offshore yet). Repowering can be helpful both from economic and conservative standpoints as the number of turbines reduces and can be better placed spatially while their output and efficiency are much higher for profit. The effectiveness of relocating hazardous turbines compared to other measures such as curtailment provides another research opportunity method that can be most economically feasible. Adaptive management can also be implemented during repowering as heights and turbine size are increasing and evolving. Additionally, the inclusion of new empirical research through adaptive management can improve efficiency in minimizing impacts during this phase and into the operational stages of the new towers.

Table 1 provides a numerical table of peer-reviewed sources aligned as 'Recommendation', 'Observation', and 'Investigation'. The measures and species group are categorized in 'known' (in black) when there are three or more investigations, 'somewhat known' (in dark grey) when there is at least one observation or one investigation, 'unknown' (in white) when there is no research at all, and 'unknown but recommended' (in light grey) when there is no observational or investigative research. A similar table is found in mitigation measures for wildlife in wind energy development, consolidating the state of knowledge - Part 2: planning, siting, and construction, and is based on its Appendix. In addition, we have removed 'Visual Deterrence' and 'Phased Development' from the table as there is no research in either mitigation measures. The discussion and table on mitigation topics of Planning, Siting, and Construction are within the article, mitigation measures for wildlife in wind energy development, consolidating the state of knowledge - Part 1: planning, siting, and construction.

\section{Outlook}

While the discussion of mitigation has increased, investigation into the efficacy of measures is critically needed. One reason is due to research still being conducted into the impacts wind facilities and turbines have on wildlife. There has been heavy focus on birds and bats as they are the most at-risk species groups, and 
research is moving into underlying mechanisms of behaviuoral responses which can provide results more beneficial to the use of mitigation. As stated in Sec. 1, the use of BACI studies and continued monitoring is needed to help in better understanding effective mitigation and can be applied to any species possibly affected by the development of a wind facility or turbine. Additionally, investigative research into offshore wind development mitigation is difficult due to financial, time, and employment constraints, and more stringent weather conditions (Krone et al., 2013). Lastly, mitigation research for not at-risk species (i.e. fish, benthos, and non-volant species) is minimal as the need for long-term impact studies first must be analysed to see if displacement, barriers, or reduced fitness occurs and to what extent.

Furthermore, we lack empirical data and discussion on the financial constraints and economic aspects in allowing mitigation measures to be used and become more efficient. This is crucial as the balance between economic interests and conservation interests should be placed at a higher spectrum for better mitigation strategies benefitting all stakeholders. This includes the need for better transparency and cooperation from facilitators on providing monitoring results, data collection, and analysis. Measures are only as effective as the willingness for facilitators to work with researchers, and to understand and use measures most applicable based on the facility turbine(s). Decisively, the need for further investigation into mitigation measure efficacy, as well as further research into the financial and economic players within wildlife mitigation is the next primary step to improve, implement, and encourage mitigation in wind energy.

It is crucial to understand beneficial impacts on wildlife do not substitute or completely counterbalance mitigation of negative impacts. For instance, as offshore turbine foundations can provide beneficial artificial reef habitats, thus being a significant effect, it does not excuse the need or use to provide mitigation measures. This can be concluded based on EIA research done by Vaissière et al. (2014). While the conservation status of endangered species must take priority, compensation should be necessary as impacts, in the majority of cases, will always remain. Additionally, the use of policies establishing critical habitats for affected species such as the U.S. Habitat Conservation Plan (HCP), which helps implement compensation. Developers should aim for net-gain from any impacts, as the issue of cumulative effects from wind energy development will never be fully known.

To close, there will always be ever remaining uncertainties. Research focusing on site-species-season specificity (Reichenbach, 2013) can help reduce these uncertainties, but some mitigation measures cannot always be proven effective or not. There are (and will be) effective measures (i.e. output), but the results will not continuously be clear (i.e. outcome), and accepting uncertainties at the beginning 
of wind facility planning stages can easily improve the effectiveness of mitigation and minimizing impacts over the lifetime of the project.

\section{Acknowledgements}

This article evolved from research in 'Impacts of wind energy development on wildlife - an international synopsis' carried out by the Environmental Assessment and Planning Research Group of the Berlin Institute of Technology (TU Berlin), funded by the German Federal Ministry for Economic Affairs and Energy (BMWi) on the basis of a decision by the German Bundestag. Earlier versions of the manuscript benefitted from comments offered by Juliane Bauer and anonymous reviewers.

\section{References}

Sources used in Parts 1 and 2 are found within Part 1's references list.

Allison, TD (2012). Eagles and wind energy: Identifying research priorities. A white paper of the Washington, D.C.: American Wind Wildlife Institute.

Andersson, MH and MC Öhman (2010). Fish and sessile assemblages associated with wind-turbine constructions in the Baltic Sea. Marine and Freshwater Research 61(6):642-650.

Arizona Game and Fish Department (2008). Guidelines for reducing impacts to wildlife from wind energy development in Arizona [Accessed 15 April 2016].

Arnett, EB et al., (2006). An evaluation of the use of acoustic monitoring to predict bat fatality at a proposed wind facility in southcentral Pennsylvania: An annual report submitted to the bats and wind energy cooperative. Austin, TX: Bat Conservation International. http://www.batsandwind.org/pdf/precon_pa.pdf [Accessed 25 June 2014]. Arnett, EB et al., (2009). Effectiveness of changing wind turbine cut-in speed to reduce bat fatalities at wind facilities: An annual report prepared for the bats and wind energy cooperative. Austin, TX: Bat Conservation International. http://www.batsandwind.org/ pdf/Curtailment\%20Final\%20Report\%205-15-10\%20v2.pdf.

Arnett, EB, R Barclay and CD Hein (2013a). Thresholds for bats killed by wind turbines. Frontiers in Ecology and the Environment 11(4):171.

Arnett, EB, CD Hein, MR Schirmacher, MMP Huso and JM Szewczak (2013b). Evaluating the effectiveness of an ultrasonic acoustic deterrent for reducing bat fatalities at wind turbines. PLoS ONE, 8(6), e65794.

Arnett, EB, MMP Huso, MR Schirmacher and JP Hayes (2011). Altering turbine speed reduces bat mortality at wind-energy facilities. Frontiers in Ecology and the Environment, 9(4), 209-214. 


\section{Gartman et al.}

Ashley, MC, SC Mangi and LD Rodwell (2014). The potential of offshore windfarms to act as marine protected areas - A systematic review of current evidence. Marine Policy, $45,301-309$.

Baerwald, EF and R Barclay (2009). Geographic variation in activity and fatality of migratory bats at wind energy facilities. Journal of Mammology, 90(6), 1341-1349.

Baerwald, EF, J Edworthy and M Holder and R Barclay (2009). A large-scale mitigation experiment to reduce bat fatalities at wind energy facilities. The Journal of Wildlife Management, 73(7), 1077-1081.

Ballasus, H, K Hill and O Hüppop (2009). Gefahren künstlicher Beleuchtung für ziehende Vögel und Fledermäuse. Berichte zum Vogelschutz, (46), 127-157.

Barrios, L and A Rodríguez (2004). Behavioural and environmental correlates of soaringbird mortality at on-shore wind turbines. Journal of Applied Ecology 41(1), 72-81.

Behr, O, R Brinkmann, I Niermann and F Korner-Nievergelt (2011). Akustische Erfassung der Fledermausaktivität an Windenergieanlagen. In Entwicklung von Methoden zur Untersuchung und Reduktion des Kollisionsrisikos von Fledermäusen an OnshoreWindenergieanlagen: Ergebnisse eines Forschungsvorhabens, Brinkmann R, O Behr, I Niermann and M Reich (eds.) pp. 177-286. Göttingen: Cuvillier.

Behr, O, K Hochradel, J Mages, M Nagy, F Korner-Nievergelt, I Niermann, R Simon, F Stiller, N Weber and R Brinkmann (2014). Bat-friendly operation algorithms: Reducing bat fatalities at wind turbines in central Europe. International Energy Agency's Wind Task 34.

Behr, O, L Baumbauer, K Hochradel, J Hurst, J Mages, M Nagy, F Korner-Nievergelt, I Niermann, H Reers, R Simon, N Weber and R Brinkmann (2015). "Bat-friendly" operation of wind turbines - the current status of knowledge and planning procedures in Germany. In Conf. on wind energy and wildlife impacts: Book of Abstracts, Köppel J and E Schuster (eds.) p. 17. Berlin, Germany.

Bennettm, VJ and AM Hale (2014). Red aviation lights on wind turbines do not increase bat-turbine collisions. Animal Conservation, 17(4), 354-358.

Bishop et al. (2003). Review of international research literature regarding the effectiveness of auditory bird scaring techniques and potential alternatives: A white paper. Department of Environment, Food and Rural affairs, UK.

Blew, J, G Nehls and U Prall (2013). Offshore obstruction lighting — Issues and mitigation. In: Naturvårdsverket (ed) Book of Abstracts: Conference on wind power and environmental impacts. Stockholm, Sweden, p. 31.

Boarman, WI (2003). Managing a subsidized predator population: Reducing common raven predation on desert tortoises. Environmental Management, 32(2), 205-217.

Brinkmann, R, O Behr, I Niermann and M Reich (eds.) (2011). Entwicklung von Methoden zur Untersuchung und Reduktion des Kollisionsrisikos von Fledermäusen an OnshoreWindenergieanlagen: Ergebnisse eines Forschungsvorhabens. Umwelt und Raum, Vol. 4. Göttingen: Cuvillier. 
Brotas, G, JM Oliveira and C Loureiro (2015). Wind farms and a compensatory programme for the Iberian Wolf in Portugal (Poster). In Conf. on wind energy and Wildlife impacts: Book of Abstracts, Köppel J and E Schuster (eds.) p. 98. Berling, Germany: Technische Universität Berlin.

California Energy Commission and California Department of Fish \& Game (2007). California guidelines for reducing impacts to birds and bats from wind energy development: Commission Final Report.

Camiña, Á (2011a). Ein vermeidbarer Konflikt: Geier und Windenergieanlagen. Der Falke, 58(12), 504-507.

Camiña, Á (2011b). The effects of wind farms on vultures in Northern Spain — Fatalities behavior and correction measures. In Proc. Conf. on Wind energy and Wildlife impacts, May R and K Bevanger (eds.) p. 17. NINA Report 693, Trondheim, Norway: Norwegian Institute of Nature Review.

Clarke, TL (2004). An autonomous bird deterrent system. Dissertation, University of Southern Queensland, Dept. of Mechatronics.

Cordeiro, A, M Mascarenhas and H Costa (2013). Long term survey of wind farms impacts on Common Kestrel's populations and definition of an appropriate mitigation plan. In Book of Abstracts: Conference on wind power and environmental impacts (CWE), Naturvårdsverket Rapport 6546 p. 47. Stockholm, Sweden.

Cortés-Avizanda, A, M Carrete, JA Donázar (2010). Managing supplementary feeding for avian scavengers: Guidelines for optimal design using ecological criteria. Biological Conservation, 143(7), 1707-1715.

Cryan, PM (2008). Mating behavior as a possible cause of bat fatalities at wind turbines. The Journal of Wildlife Management, 72(3), 845-849.

Dahl, EL et al., (2015). Repowering Smøla wind-power plant. An assessment of avian conflicts. NINA Report.

Davenport, J, A Smith, TA Kelly, J Lewis, J Vidao and S Villar (2011). Implementation of avian radar-SCADA interface to mitigate avian mortality at windfarms. In Proc. Conf. on wind energy and wildlife impacts, May $\mathrm{R}$ and $\mathrm{K}$ Bevanger (eds.) p. 81. NINA Report 693, Trondheim, Norway.

DeTech, Inc. (2014). Bird and bat radar systems, Merlin ARS. http://www.detect-inc.com/ avian.html.

Dooling (2002). Avian Hearing and the Avoidance of Wind Turbines: Technical Report. Dorka, U, F Straub and J Trautner (2014). Windkraft über Wald - kritisch für die Waldschnepfenbalz?: Erkenntnisse aus einer Fallstudie in Baden-Württemberg (Nordschwarzwald). Naturschutz und Landschaftsplanung, 46(3), 69-78.

Erickson, WP et al., (2004). Stateline wind project wildlife monitoring final report: Results for Period July 2001-December 2003. Cheyenne, Wyoming, \& Walla Walla Western EcoSystems Technology Inc: Washington: Northwest Wildlife Consultants, Inc.

Everaert, J and EWM Stienen (2007). Impact of wind turbines on birds in Zeebrugge (Belgium). Biodiversity and Conservation, 16(12), 3345-3359. 


\section{Gartman et al.}

Fiedler, JK et al., (2007). Results of bat and bird mortality monitoring at the expanded buffalo mountain windfarm, 2005. Tennessee, USA: Tennessee Valley Authority.

Furness, RW and S Wanless (2015). Quantifying the impact of offshore wind farms on Gannet populations: A strategic ringing project. Ringing and Migration, 29(2), 81-85.

Gaedicke, L, K Loske and F Bergen (2013). Effects of repowering wind turbines on collision risk of raptor species. In Book of Abstracts: Conference on Wind Power and Environmental Impacts (CWE), Naturvårdsverket p. 136 Rapport 6546. Stockholm, Sweden.

Ganassin, C and PJ Gibbs (2008). A review of seagrass planting as a means of habitat compensation following loss of seagrass meadow, NSW Department of Primary Industries.

Gehring, JL, P Kerlinger and A Manville (2009). Communication towers, lights, and birds: Successful methods of reducing the frequency of avian collisions. Ecological Applications, (19), 505-514.

Georgiakakis, P, E Kret, B Cárcamo, B Doutau, A Kafkaletou-Diez, D Vasilakis and E Papadatou (2012). Bat fatalities at wind farms in north-eastern greece. Acta Chiropterologica, 14(2), 459-468.

Gilsdorf, JM, SE Hygnstrom, KC VerCauteren (2002). Use of frightening devices in wildlife damage management. Integrated Pest Management Reviews, (7), 29-45.

Hanagasioglu, M et al. (2015). Investigation of the effectiveness of bat and bird detection of the DTBat and DTBird systems at Calandawind turbine. Untersuchung zur Effektivität der Fledermaus- und Vogeldetektion des bei Windturbinen mit DTBird System, Swiss Federal Office of Energy (SFOE), Research Program Wind Energy; Federal Office for the Environment (FOEN); 3MW Wind Turbine; Interwind AG; Swiss Ornithological Institute; SWILD - Urban Ecology \& Wildlife Research.

Harris, RH and RA Davis (1998). Evaluation of the efficacy of products and techniques for airport bird control, Canada: LGL Ltd. Report.

Heaton, JS, KE Nussear, TC Esque, RD Inman, FM Davenport, TE Leuteritz, PA Medica, NW Strout, PA Burgess and L Benvenuti (2008). Spatially explicit decision support for selecting translocation areas for Mojave desert tortoises. Biodiversity and Conservation 17(3), 575-590.

Hein, C (2014). Strategies to reduce bat fatalities at wind energy facilities: Working together to solve environmental effects of wind energy. International Energy Agency's Wind Task 34.

Hill, R, K Hill, R Aumüller, A Schulz, T Dittmann, C Kulemeyer and T Coppack (2014). Of birds, blades and barriers: Detecting and analysing mass migration events at alpha ventus. In Ecological Research at the Offshore Windfarm Alpha Ventus: Challenges, Results and Perspectives. Beiersdorf A and A Radeike (eds.), Germany: Springer Verlag.

Hoover (2002). The Response of Red-Tailed Hawks and Golden Eagles to Topographical Features, Weather, and Abundance of a Dominant Prey Species at the Altamont Pass Wind Resource Area, California: April 1999 — December 2000. 
Hoover, S and ML Morrison (2005). Behavior of red-tailed hawks in a wind turbine development. The Journal of Wildlife Management, 69(1), 150-159.

Horn, JW, EB Arnett and TH Kunz (2008). Behavioral responses of bats to operating wind turbines. The Journal of Wildlife Management, 72(1), 123-132.

Hötker, H, et al., (2006). Impacts on Biodiversity of Exploitation of Renewable Energy Sources: The Example of Birds and Bats, NABU Bergenlausen: Michael-Otto-Institut.

Hüppop, O, J Dierschke, K Exo, E Fredrich and R Hill (2006). Bird migration studies and potential collision risk with offshore wind turbines. Ibis 148, 90-109.

Hurst, J, H Schauer-Weisshahn and R Brinkmann (2013). Using automatic measurements of bat activity to develop turbine-specific curtailment algorithms - A case study in two wind parks. In Book of Abstracts: Conference on wind power and environmental impacts (CWE), Naturvårdsverket Rapport 6546 p. 147. Stockholm, Sweden: Naturvårdsveret.

Inger, R, MJ Attrill, S Bearhop, AC Broderick, W James Grecian, DJ Hodgson, C Mills, E Sheehan, SC Votier, MJ Witt and BJ Godley (2009). Marine renewable energy: Potential benefits to biodiversity? An urgent call for research. Journal of Applied Ecology 46(6), 1145-1153.

Johnson, GD, WP Erickson, MD Strickland, M Shepherd, D Shepherd and S Sarappo (2003). Mortality of bats at a large-scale wind power development at Buffalo Ridge, Minnesota. The American Midland Naturalist, 150(2), 332-342.

Johnson, GD, MK Perlik, WP Erickson and MD Strickland (2004). Bat activity, composition, and collision mortality at a large wind plant in Minnesota. Wildlife Society Bulletin, 32(4), 1278-1288.

Johnson, JS, KS Watrous, GJ Giumarro, TS Peterson, SA Boyden and MJ Lacki (2011). Seasonal and geographic trends in acoustic detection of tree-roosting bats. Acta Chiropterologica, 13(1), 157-168.

Kerlinger, P, JL Gehring, WP Erickson, R Curry, A Jain and J Guarnaccia (2010). Night migrant fatalities and obstruction lighting at wind turbines in north America. The Wilson Journal of Ornithology, 122(4), 744-754.

Korner-Nievergelt, F, P Korner-Nievergelt, O Behr, I Niermann, R Brinkmann and B Hellriegel (2011). A new method to determine bird and bat fatality at wind energy turbines from carcass searches. Wildlife Biology, 17(4), 350-363.

Krone, R, L Gutow, TJ Joschko and A Schröder (2013). Epifauna dynamics at an offshore foundation - Implications of future wind power farming in the North Sea. Marine Environmental Research, 85(0), 1-12.

Kunz, TH, EB Arnett, B Cooper, WP Erickson, RP Larkin, T Mabee, ML Morrison, MD Strickland and JM Szewczak (2007). Assessing impacts of wind-energy development on nocturnally active birds and bats: A guidance document. The Journal of Wildlife Management, 71(8), 2449-2486.

van de Laar, FJT (2007). Green light to birds: Investigation into the effect of bird-friendly lighting.www.waddenzee.nl/fileadmin/content/Dossiers/Energie/pdf/green_light_to_ birdsNAM.pdf. 


\section{Gartman et al.}

Lagrange, H, P Rico, A Ughetto, F Melki and C Kerbiriou (2013). Chirotech: Six years of research (2006 - 2012). Presentation CWE, Stockholm, Sweden.

Landesamt für Umweltschutz Sachsen-Anhalt, (2014). Artenhilfsprogramm Rotmilan des Landes Sachsen-Anhalt. Berichte des Landesamtes für Umweltschutz Sachsen-Anhalt, Landesamt für Umweltschutz Sachsen-Anhalt (LAU).

Lucas, M de, M Ferrer, MJ Bechard and A Muñoz Gallego (2012). Griffon vulture mortality at wind farms in southern Spain: Distribution of fatalities and active mitigation measures. Biological Conservation, 147(1), 184-189.

Mammen, U, K Mammen, N Heinrichs and A Resetaritz (2011). Red kite (Milvus milvus) fatalities at wind turbines - Why do they occur and how they are to prevent? In Proc. Conf. on wind energy and wildlife impacts, May R and K Bevanger (eds.), NINA Report 693, Trondheim, Norway, p. 108.

Martin, C (2015). Effectiveness of operational mitigation in reducing bat mortality and an assessment of bat and bird fatalities at the Sheffield Wind Facility, Vermont. Master of Sciences, Texas Tech University.

Martin, GR (2011). Understanding bird collisions with manmade objects: A sensory ecology approach. Ibis, (153) 239-254.

Martin, GR and JM Shaw (2010). Bird collisions with power lines: Failing to see the way ahead? Biological Conservation, 143(11), 2695-2702.

Martínez-Abraín, A, G Tavecchia, HM Regan, J Jiménez, M Surroca and D Oro (2012). Effects of wind farms and food scarcity on a large scavenging bird species following an epidemic of bovine spongiform encephalopathy. Journal of Applied Ecology, 49(1), 109-117.

Millon, L, J Julien, R Julliard and C Kerbiriou (2015). Bat activity in intensively farmed landscapes with wind turbines and offset measures. Ecological Engineering, 75, 250-257.

Muños Gallego, A, M de Lucas, E Casado and M Ferrer (2011). Raptor mortality in wind farms of southern Spain: Mitigation measures on a major migration bottleneck area. In Proc. Conf. on wind energy and wildlife impacts, May $\mathrm{R}$ and Bevanger $\mathrm{K}$ (eds.) NINA Report 693, Trondheim, Norway, p. 42.

Nicholls, B and PA Racey (2007). Bats avoid radar installations: Could electromagnetic fields deter bats from colliding with wind turbines? PLOS ONE, 2(3), e297.

Nicholls, B and PA Racey (2009). The aversive effect of electromagnetic radiation on foraging bats - A possible means of discouraging bats from approaching wind turbines. PLoS ONE, 4(7), e6246.

Nugent, D and BK Sovacool (2014). Assessing the lifecycle greenhouse gas emissions from solar PV and wind energy: A critical meta-survey. Energy Policy, 65, 229-244.

Orloff, SG et al., (1992). Wind turbine effects on avian activity, habitat use, and mortality in Altamont Pass and Solano County wind resource areas, 1989-1991: Final Report, California Energy Commission. 
Paula, A (2015). Compensation scenarios to deal with wind farm's impacts on birds: The challenges of moving from theory to practice. In: Köppel J and E Schuster (eds.), Conf. on wind energy and wildlife impacts: Book of Abstracts. Berlin, Germany, p. 51.

Paula, A, J Santos, A Cordeiro, HM Costa, M Mascarenhas and C Reis (2011). Managing habitat for prey recovery - An off-site mitigation tool for wind farms' impacts on top avian predators. In Proc. Conf. on wind energy and wildlife impacts, May $\mathrm{R}$ and Bevanger K (eds.) NINA Report 693, Trondheim, Norway, p. 44.

Pearce, B, JM Fariñas-Franco, C Wilson, J Pitts, A deBurgh and PJ Somerfield (2014). Repeated mapping of reefs constructed by Sabellaria spinulosa Leuckart 1849 at an offshore wind farm site. Continental Shelf Research, 83, 3-13.

Petersen, JK and T Malm (2006). Offshore windmill farms: Threats to or possibilities for the marine environment. Ambio, 35(2), 75-80.

Piorkowski, MD, AJ Farnsworth, M Fry, RW Rohrbaugh, JW Fitzpatrick and KV Rosenberg (2012). Research priorities for wind energy and migratory wildlife. The Journal of Wildlife Management, 76(3), 451-456.

Poot, H, BJ Ens, H de Vries, Donners, AH Maurice, MR Wernand and JM Marquenie (2008). Green light for nocturnally migrating birds. Ecology and Society, 13(2), 47.

Rasran, L, T Dürr and H Hötker (2010). Analysis of collision victims in Germany. In Birds of Prey and Wind Farm: Analysis of Problems and Possible Solutions, Hötker H, (ed.), pp. 26-30.

Reichenbach, M (2013). The Dilemma of the Planner - How to handle birds and bats in the planning process of wind farms - Examples, problems and solutions from Germany. In Book of Abstracts: Conf. on wind power and environmental impacts (CWE), p. 89. Naturvårdsverket: Stockholm, Sweden.

Reubens, JT, S Degraer and M Vincx (2011). Aggregation and feeding behaviour of pouting (Trisopterus luscus) at wind turbines in the Belgian part of the North Sea. Fisheries Research, 108(1), 223-227.

Rich, C and T Longcore (eds.) (2006). Ecological Consequences of Artificial Night Lighting. Island Press, Washington DC.

Riopérez, A and M Puente (2013). DTBird: A tool for bird monitoring and bird mortality reduction in wind farms. In: Naturvårdsverket (ed.), Book of Abstracts: Conference on wind power and environmental impacts. Stockholm, Sweden, p. 12.

Robson, P (2011). Review of Hen Harrier breeding and flight activity near a windfarm in Argyll (Poster). Conference on wind energy and wildlife impacts 2011. Trondheim, Norway, http://www2011.nina.no

Rydell, J, L Bach, M Dubourg-Savage, M Green, L Rodrigues and A Hedenström (2010). Bat mortality at wind turbines in Northwestern Europe. Acta Chiropterologica, 12(2), 261-274.

Santos, M, R Bastos, P Travassos, R Bessa, M Repas and JA Cabral (2010). Predicting the trends of vertebrate species richness as a response to wind farms installation 


\section{Gartman et al.}

in mountain ecosystems of northwest Portugal. Ecological Indicators 10(2), 192-205.

Sheppard, JK, A McGann, M Lanzone, A Walsh, M Wallace and R Swaisgood (2014). Curtailing avian impacts with wind turbines using GSM/GPS tracking telemetry that incorporates autonomous geofence alerts. Presentation at NWCC Research Meeting X, Broomfield, Colorado.

Singh, K, ED Baker and MA Lackner (2015). Curtailing wind turbine operations to reduce avian mortality. Renewable Energy, 78, 351-356.

Smallwood, KS (2007). Estimating wind turbine-caused bird mortality. The Journal of Wildlife Management, 71(8), 2781-2791.

Smallwood, KS (2008). Wind power company compliance with mitigation plans in the Altamont Pass Resource Area. Environmental \& Energy Law \& Policy Journal 2(2), 229-285.

Smallwood, KS (2010). Assessment of three proposed adaptive management plans for reducing raptor fatalities in the altamont pass wind resource area.

Smallwood, KS (2015). The challenges of repowering. In Conf. on wind energy and Wildlife impacts: Book of Abstracts, Köppel J and E Schuster (eds.), p. 11.

Smallwood, KS, DA Bell, SA Snyder and JE DiDonato (2010). Novel scavenger removal trials increase wind turbine-caused avian fatality estimates. The Journal of Wildlife Management, 74(5), 1089-1097.

Smallwood, KS and B Karas (2009). Avian and bat fatality rates at old-generation and repowered wind turbines in California. The Journal of Wildlife Management, 73(7), 1062-1071.

Smallwood, KS and L Neher (2004). Repowering the APWRA: Forecasting and minimizing avian mortality without significant loss of power generation, California energy commission; PIER energy-related environmental research program. http://www.energy. ca.gov/2005publications/CEC-500-2005-005/CEC-500-2005-005.pdf.

Smallwood, KS and L Neher (2009). Map-based repowering of the altamont pass wind resource area based on burrowing owl burrows, raptor flights, and collisions with wind turbines, california energy commission; PIER energy-related environmental research program.http://www.energy.ca.gov/2009publications/CEC-500-2009-065/CEC-5002009-065.PDF.

Smallwood, KS and CG Thelander (2008). Bird mortality in the altamont pass wind resource area, California. The Journal of Wildlife Management, 72(1), 215-223.

Smyth, K, N Christie, D Burdon, JP Atkins, R Barnes and M Elliott (2015). Renewablesto-reefs? - Decommissioning options for the offshore wind power industry. Marine Pollution Bulletin, 90(1-2), 247-258.

Sutter, C, K Martin and C Grandgent (2012). Condor detection and alerting system. US National Wind Coordinating Collaborative (NWCC), Research Meeting IX November 27-30, 2012, Denver, Colorado, http://www.nationalwind.org/research/meetings/ research-meeting-ix/ 
Thelander, CG and L Rugge (2000). Avian risk behavior and fatalities at the altamont wind resource area: March 1998 to February 1999, Predatory Bird Research Group, University of California, Santa Cruz.

Tomé, R, F Canário, A Leitão, N Pires, P Cardoso and M Repas (2015). Radar assisted shutdown on demand ensures zero soaring bird mortality at a wind farm located in a migratory flyway. In: Köppel $\mathbf{J}$ and E Schuster (eds.), Conf. on wind energy and wildlife impacts: Book of Abstracts, Berlin, Germany, p. 66.

Turowicz, P, P Zieliński, A Kucmus, A Walkowiak and J Furmankiewicz (2013). Foraging activity of bats around artificial light source and possible usage for conservation. In Book of Abstracts: Conf. on wind power and environmental impacts (CWE), p. 101. Stockholm, Sweden: Naturvårdsverket.

Villegas-Patraca, R and L Herrera-Alsina (2015). Migration of Franklin's Gull (Leucophaeus pipixcan) and its variable annual risk from wind power facilities across the Tehuantepec Isthmus. Journal for Nature Conservation, 25, 72-76.

Voigt, CC, LS Lehnert, G Petersons, F Adorf and L Bach (2015). Wildlife and renewable energy: German politics cross migratory bats. European Journal of Wildlife Research, 61(2), 213-219.

Walker, D, M McGrady, A McCluskie, M Madders and DRA McLeod (2005). Resident Golden Eagle ranging behaviour before and after construction of a windfarm in Argyll. Scottish Birds, (25), 24-40.

Weller, TJ and JA Baldwin (2012). Using echolocation monitoring to model bat occupancy and inform mitigations at wind energy facilities. The Journal of Wildlife Management, 76(3), 619-631.

Wellig, S and R Arlettaz (2013). Mitigating the potential negative effects of tall wind turbines on bats: Vertical activity profiles and relationships to wind speed. In Book of Abstracts: Conf. on wind power and environmental impacts (CWE), p. 108. Stockholm, Sweden: Naturvårdsverket.

Wilson, JC and M Elliott (2009). The habitat-creation potential of offshore wind farms. Wind Energy, 12(2), 203-212. 